Dev Neurosci 2018;40:617-626

DOI: $10.1159 / 000495879$
Received: September 28, 2018

Accepted after revision: November 27, 2018

Published online: March 5, 2019

\title{
HIF 1a Signaling in the Endogenous Protective Responses after Neonatal Brain Hypoxia-Ischemia
}

\author{
Xiao Liang $^{\mathrm{a}}$ Xuemei Liu ${ }^{\mathrm{b}}$ Fuxin Lu ${ }^{\mathrm{c}}$ Yunling Zhang ${ }^{\mathrm{a}}$ Xiangning Jiang ${ }^{\mathrm{c}}$ \\ Donna M. Ferriero ${ }^{c, d}$ \\ ${ }^{a}$ Xiyuan Hospital, China Academy of Chinese Medical Sciences, Beijing, China; ${ }^{b}$ Central Laboratory, Dongfang \\ Hospital, Beijing University of Chinese Medicine, Beijing, China; ' $D$ epartment of Pediatrics, University of California \\ San Francisco, San Francisco, CA, USA; d Department of Neurology, University of California San Francisco, \\ San Francisco, CA, USA
}

\section{Keywords}

Brain · Development · Hypoxia/ischemia $\cdot$ Hypoxia-

inducible factor $1 a$

\begin{abstract}
Hypoxia-inducible factor $1 \mathrm{a}$ (HIF1a) is a key regulator of oxygen homeostasis, and its target genes mediate adaptive, protective, and pathological processes. The role of HIF1a in neuronal survival is controversial and the brain maturation stage is important in determining its function in brain ischemia or hypoxia-ischemia (HI). In this study, we used neuronspecific HIF1a knockout mice at postnatal day 9 (P9), and immature cortical neurons (days 7-8 in vitro) treated with the HIF1a inhibitor 2-methoxyestradiol (2ME2) or stabilizer dimethyloxalylglycine (DMOG), to examine the function of neuronal HIF1a in neonatal HI in vivo (Vannucci model) and in vitro (oxygen glucose deprivation, OGD). Inhibition of HIF1 a with 2ME2 in primary neurons or deletion of neuronal HIF1a in P9 mice increased both necrotic and apoptotic cell death following $\mathrm{HI}$, as evaluated by the protein levels of 145/150-kDa and 120-kDa spectrin breakdown products 24 $\mathrm{h}$ after HI. DMOG attenuated neuronal death right after OGD. Acute pharmacological manipulation of HIF1a synchronous-
\end{abstract}

ly regulated the expression of its targets, vascular endothelial growth factor (VEGF) and erythropoietin (Epo), in the same manner. The in vivo findings agree with our previous data using the same HIF1a-deficient mice at an earlier age. This study confirms the role of neuronal HIF1a signaling in the endogenous protective responses following $\mathrm{HI}$ in the developing brain.

(c) 2019 S. Karger AG, Basel

\section{Introduction}

Hypoxic-ischemic encephalopathy (HIE) is an important complication at birth and a significant cause of neonatal death. Moderate to severe HIE is usually associated with poor neurological outcomes including motor impairment or cognitive deficits [1]. Strategies that boost endogenous brain protection or stimulate regenerative repair hold the promise of translating research into clinical practice. One such strategy is targeting the transcription factor hypoxia-inducible factor 1 (HIF1), which plays a critical role in regulating cellular adaptation to hypoxia and oxidative stress [2-4]. HIF1 consists of 2 subunits, HIF1 $\alpha$ and HIF1 $\beta$. HIF1 $\beta$ does not respond to
KARGER

(C) 2019 S. Karger AG, Basel

E-Mail karger@karger.com

www.karger.com/dne
Donna M. Ferriero

Departments of Pediatrics and Neurology

University of California, San Francisco, 675 Nelson Rising Lane Rm 415

San Francisco, CA, 94158 (USA)

E-Mail Donna.Ferriero@ucsf.edu 
changes in oxygen tension, while the stability, subcellular localization, and transcriptional activity of HIF $1 \alpha$ are especially affected by the oxygen level $[5,6]$. In normoxic conditions, HIF $1 a$ is rapidly degraded by the prolyl hydroxylase (PHD)-dependent proteasomal system, but under hypoxia HIF1 a protein degradation is prevented $[7,8]$. Upon its accumulation and phosphorylation, HIF $1 \alpha$ dimerizes with HIF1 $\beta$, translocates into the nucleus, and promotes the transcription of hypoxia response element (HRE)-containing target genes that are involved in energy metabolism, redox homeostasis, erythropoiesis, vascular remodeling, and other processes $[9,10]$.

Induction of HIF $1 \alpha$ has been reported in the ischemic penumbra in adult rats and mice, as well as in the neonatal brain following hypoxia-ischemia (HI) [11-15]. The role of HIF1a in mediating protective or injury mechanisms remains controversial, as it has been shown that HIF1 $\alpha$ upregulates both pro- and antisurvival genes [1619]. The discrepancies are related to the model of brain injury, the timing and duration of HIFla stimulation or inhibition, the pathways that are activated downstream of HIF1a, the cell type in which HIF1a is induced, and the intercellular communication to transmit the HIF1a signaling. Selective loss of HIF1a function in astrocytes leads to different outcomes of neuron-specific inactivation of HIF1a [20]. Using a Cre-loxP-mediated conditional knockout approach, we have shown that deficiency in forebrain neuronal HIF1 $\alpha$ caused more severe cortical injury than in wild-type (WT) littermates without HIF1a deletion [21]. However, the underlying mechanisms are not clear.

In this study, to further dissect out the specific contribution of HIF1 $\alpha$ in neuronal cell death/survival, we used pharmacological strategies with a known HIF1a inhibitor 2-methoxyestradiol (2ME2), or a PHD inhibitor dimethyloxalylglycine (DMOG) that stabilizes HIF $1 \alpha$, to manipulate HIF1 $\alpha$ levels in immature primary cortical neurons. We investigated whether acute manipulation of HIF1 a expression has any impact on neuronal viability, as well as its effects on the HIF1a substrates, vascular endothelial growth factor (VEGF) and erythropoietin (Epo), both of which are proven to be beneficial in brain repair in rodent models of neonatal $\mathrm{HI}$ and neonatal stroke [22-26].

The maturation stage of the brain at the time of the HI insult is another important contributor to determine injury evolution, recovery, and repair. Our previous work showed that HIF1a was upregulated in postnatal day 7 (P7) mice following neonatal HI $[21,27]$, in P10 rats in a neonatal stroke model [28], and after treatment with des- feroxamine (an iron chelator that could stabilize HIF1 $\alpha$ ) in neonatal stroke [29], or in primary hippocampal cultures undergoing oxygen glucose deprivation (OGD), an in vitro paradigm of $\mathrm{HI}[30]$. HIF1 $\alpha$-deficient mice had increased brain injury at P7 in response to $\mathrm{HI}$ [21]. At the same age, hypoxic preconditioning alleviated brain damage in the WT mice, but not in the HIF1a knockout (KO) mice [27]. These studies support the notion that HIF1a plays a role in endogenous protective mechanisms and is important for hypoxic preconditioning in the neonatal brain. The P7 mouse brain is equivalent to the human brain late preterm, while the P9-P10 brain more adequately mimics the brain of full-term human infants and is therefore more relevant for studies of HIE. We chose to use P9 neuron-specific HIF1a KO mice for the HI model in this study to confirm the in vitro data and the results obtained with P7 mice.

\section{Materials and Methods}

C57BL/6 mice at embryonic day 15 (Charles River Laboratories Inc., Wilmington, MA, USA) were used for primary cortical neuronal culture. The mice that carry homozygous loxP-flanking exon 2 of HIF1a alleles were bred with heterozygous mice expressing Cre recombinase under the control of the calcium/ calmodulin-dependent kinase II a (CaMKIIa) promoter to produce mice with a forebrain-predominant, neuron-specific deletion of HIF1a, as well as their WT littermates without the deletion [31-34]. All mice showing negative on PCR for the Cre gene were considered WT. Both sexes were used for neonatal HI procedure at $\mathrm{P} 9$.

\section{Neonatal Brain HI Injury}

Neonatal HI was performed as previously described with the Vannucci procedure [35]. At P9, the pups were anesthetized with isoflurane (2-3\% isoflurane/balance oxygen) and the left common carotid artery was electrocauterized. The animals were allowed to recover for $1 \mathrm{~h}$ with their dam and were then exposed to $60 \mathrm{~min}$ of hypoxia in a humidified chamber at $37^{\circ} \mathrm{C}$ with $10 \%$ oxygen/balance nitrogen. Sham-operated control animals received isoflurane anesthesia and exposure of the left common carotid artery, without electrocauterization or hypoxia. HI and sham animals were returned to their dams until they were euthanized.

\section{Primary Cortical Neuronal Culture}

Brains were removed from embryonic day 15 (E15) C57BL/6 mice [36] and maintained in high-glucose DMEM with $25 \mu \mathrm{M}$ of 2-mercaptoethanol at $4{ }^{\circ} \mathrm{C}$ during dissection. Cortices were dissected and dissociated in trypsin (0.05\% with EDTA) and DNAse $(10 \mu \mathrm{g} / \mathrm{mL})$ and then resuspended in neurobasal (NB) medium with $2 \%$ B27 and $1 \mathrm{~mm}$ glutamine supplement (Gibco, Rockville, MD, USA). The cells were plated onto poly-D-lysine-precoated 96-well plates or 35-mm dishes (Corning Life Sciences, Tewksbury, MA, USA) at a density of $1 \times 10^{5}$ cells $/ \mathrm{cm}^{2}$. The cultures 
were kept at $37^{\circ} \mathrm{C}$ in a humidified incubator with a $5 \% \mathrm{CO}_{2}$ atmosphere. Three days after plating, half of the medium was replaced with the NB medium with 5-fluoro-2'-deoxyuridine ( $4 \mu \mathrm{g} /$ $\mathrm{mL})$ and uridine $(20 \mu \mathrm{g} / \mathrm{mL})$ to inhibit growth of nonneuronal cells. The neurons were used at 7-8 days in vitro for OGD experiments.

\section{OGD and Drug Treatment}

Briefly, the medium was washed out twice and replaced with NB medium without glucose (UCSF Cell Culture Facility) supplemented with B27/glutamine. Cultures were transferred to a humidified modular incubator chamber (Billups-Rothenberg Inc., Del Mar, CA, USA) and flushed with a gas mixture consisting of $95 \% \mathrm{~N}_{2} / 5 \% \mathrm{CO}_{2}$ for $5 \mathrm{~min}$. The chamber was then sealed and kept at $37^{\circ} \mathrm{C}$ in an incubator for $6 \mathrm{~h}$. The oxygen concentration was maintained at $0.3-0.5 \%$, monitored by an oxygen analyzer (MSA medical products, Pittsburgh, PA, USA) throughout the experiment. OGD was ended by changing the medium to regular NB medium with glucose and returning the cells to a normoxic incubator. The control cells underwent the same medium change but with regular NB medium and were placed in a normoxic incubator [36]. 2ME2 (Sigma-Aldrich Corp, MO, USA) was constituted in DMSO as a stock solution, and further diluted in the culture medium to a final concentration of $50 \mu \mathrm{M}$. DMSO was diluted in the same manner to a final concentration of $0.5 \%$ as the vehicle control. DMOG (Sigma) was dissolved in the medium and used at 25 $\mu \mathrm{M}$ final concentration. The drugs were maintained during OGD and for $24 \mathrm{~h}$ after OGD.

\section{Extraction of Nuclear/Cytoplasmic Fractions}

The cortices from HIF1a WT and KO mice were dissected 24 $\mathrm{h}$ after the $\mathrm{HI}$ procedure, snap-frozen and stored at $-80^{\circ} \mathrm{C}$ until use. Nuclear and cytoplasmic proteins were extracted with NE$\mathrm{PER}^{\mathrm{TM}}$ nuclear and cytoplasmic extraction reagents (Pierce Biotechnology, Rockford, IL, USA) according to the manufacturer's protocol. Briefly, the tissue was homogenized in $250 \mu \mathrm{L}$ ice-cold CER I buffer with Halt ${ }^{\mathrm{TM}}$ protease and phosphatase inhibitors (Pierce Biotechnology). After incubation with $13.75 \mu \mathrm{L}$ CER II buffer and vortex, the sample was centrifuged for $10 \mathrm{~min}$ at $16,000 \mathrm{~g}$ at $4^{\circ} \mathrm{C}$ and the supernatant was saved as the cytoplasmic extract. The pellet was resuspended in $100 \mu \mathrm{L}$ ice-cold NER buffer, shaken at $1,500 \mathrm{rpm}$ in the cold room for $20 \mathrm{~min}$, and centrifuged at $16,000 \mathrm{~g}$ at $4^{\circ} \mathrm{C}$ for $30 \mathrm{~min}$. The resultant supernatant was considered as the nuclear extract. The cytoplasmic and nuclear protein aliquots were stored at $-80^{\circ} \mathrm{C}$ until use. Protein concentrations were measured by BCA assay kit (Pierce). The nuclear and cytosol protein was prepared from primary cortical neurons using the same kit.

\section{Western Blot}

For Western blot analysis, equal amounts of protein samples (25-30 $\mu \mathrm{g}$ of cytoplasmic protein or $10-15 \mu \mathrm{g}$ of nuclear protein) were applied to $4-12 \%$ Bis-Tris SDS polyacrylamide gel electrophoresis and transferred to a PVDF membrane. The blots were probed with the following primary antibodies overnight at $4{ }^{\circ} \mathrm{C}$ : rabbit anti-HIF1a (Noves Biologicals LLC, Littleton, CO, USA); rabbit anti-Epo (Santa Cruz Biotechnology Inc.; Dallas, TX, USA); rabbit anti-VEGF (Santa Cruz Biotechnology Inc.); rabbit anti-histone 3 (Cell Signaling Technology, Boston, MA, USA); mouse anti- $\alpha$ spectrin (Millipore, Billerica, MA, USA) and $\beta$-actin (Santa

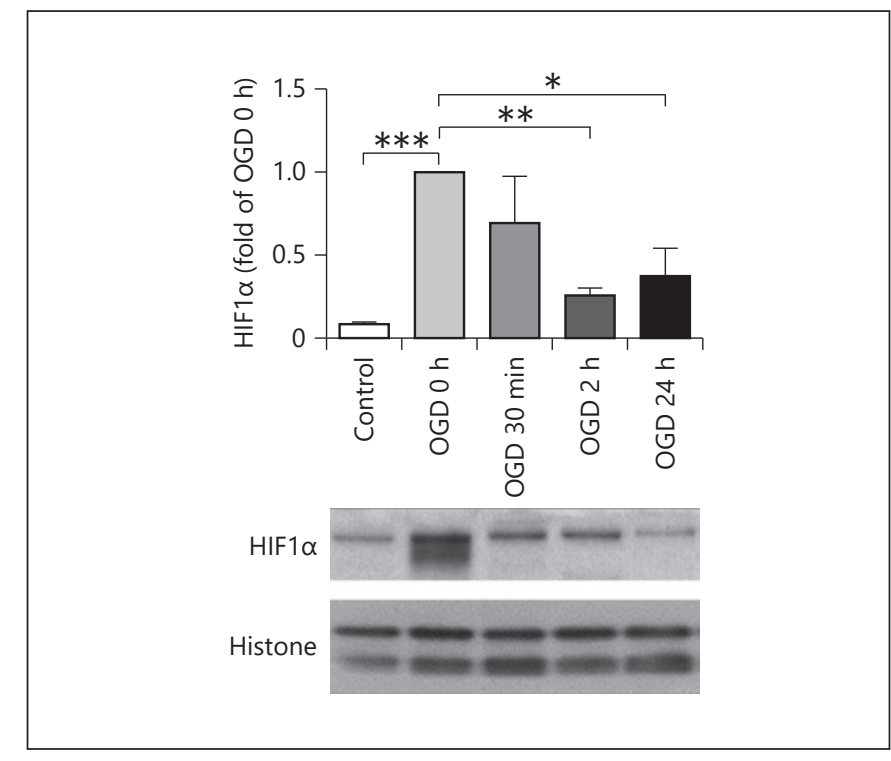

Fig. 1. The time course of HIF1a expression after OGD in primary cortical neurons. HIF1a expression peaked immediately after OGD $(0 \mathrm{~h})$ and decreased over time after reoxygenation $\left({ }^{*} p<0.05\right.$, ${ }^{* *} p<0.01$ vs. OGD $0 \mathrm{~h} ;{ }^{* * *} p<0.001$ vs. control cells; $\left.n=4-5\right)$.

Cruz Biotechnology Inc.). Horseradish peroxidase-conjugated goat anti-rabbit or goat anti-mouse secondary IgG antibodies (Santa Cruz Biotechnology Inc.) were used, and the signal was visualized with enhanced chemiluminescence (Amersham, GE Healthcare). Image J software was used to measure the mean optical densities (OD) and the area of protein signal on radiographic film after scanning.

\section{LDH Assay}

This assay was carried out with the primary neurons cultured on the 96-well plates in $100 \mu \mathrm{L}$ of medium. Neuronal cell death was quantified by a colorimetric cytotoxicity detection kit (Roche, Indianapolis, IN, USA) based on the measurement of lactate dehydrogenase (LDH) activity released from the damaged/dead cells into the culture medium. Fifty microliters of medium were collected immediately after OGD $(0 \mathrm{~h})$ from the control or OGD-treated wells to represent cell death during the $6 \mathrm{~h}$ of OGD, and again at $24 \mathrm{~h}$ after OGD to indicate cell death during $24 \mathrm{~h}$ of reoxygenation. At the end of $24 \mathrm{~h}$, the medium was completely changed, and the plates were frozen at $-80^{\circ} \mathrm{C}$ for at least $2 \mathrm{~h}$ and then thawed. Another $50 \mu \mathrm{L}$ of medium was collected to calculate LDH released from the cells that survived OGD. The percentage of cell death was expressed as: (LDH value at $0 \mathrm{~h}+$ at $24 \mathrm{~h}) /(\mathrm{LDH}$ value at $0 \mathrm{~h}+$ at $24 \mathrm{~h}+$ after freeze-thaw cycle) $\times 100$.

\section{Statistical Analysis}

$\mathrm{LDH}$ results and optical density data from Western blot are presented as mean \pm SD and were evaluated statistically using the SAS Wilcoxon-Mann-Whitney test. Differences were considered significant at $p<0.05$. 
Fig. 2. Manipulation of HIF1a protein by 2ME2 and DMOG 2ME2 inhibited HIF1a expression at $0 \mathrm{~h}$, while DMOG stabilized HIF1a for at least $24 \mathrm{~h}\left({ }^{*} p<0.05,{ }^{* *} p<\right.$ 0.01 vs. OGD; ${ }^{* * *} p<0.001$ vs. control cells; vehicle was $0.5 \%$ DMSO. $n=4-6$ ).
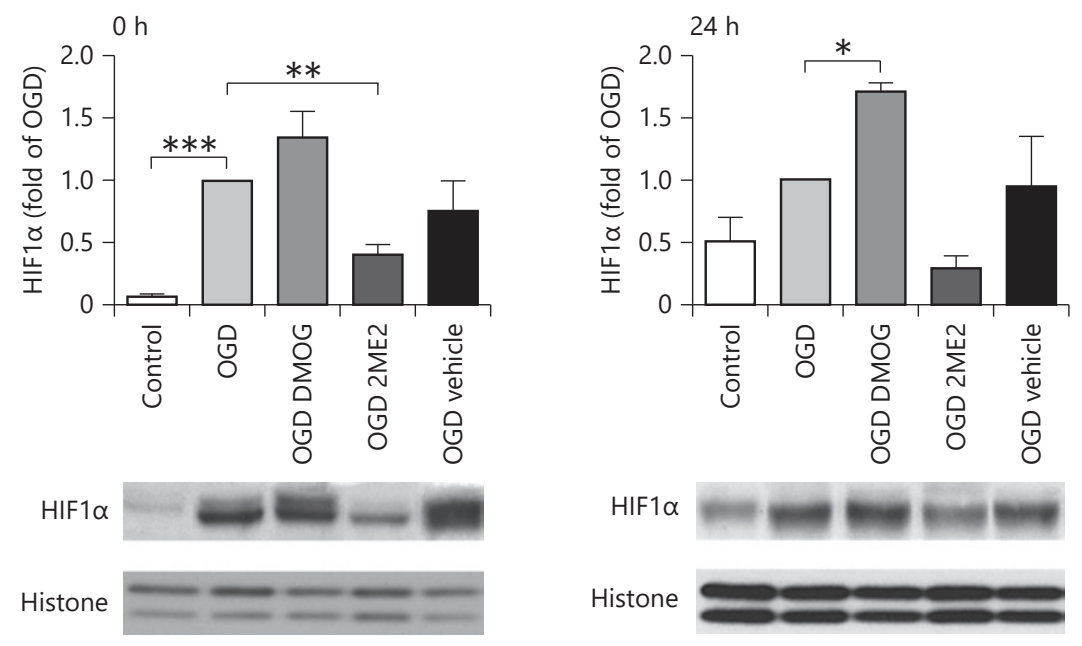

HIF1 $\alpha$

Histone

\section{Results}

Pharmacological Manipulation of HIF1 $\alpha$ Protein in Primary Cortical Neurons

The expression of HIF1a protein was measured by Western blot at different time points following OGD, an in vitro model of HI. Figure 1 showed that HIF1a accumulated during the $6 \mathrm{~h}$ of OGD (measured immediately after OGD, i.e., OGD $0 \mathrm{~h}$ ) and was degraded upon reoxygenation. HIF1 a expression decreased over time up until 24 h. 2ME2, but not the vehicle control (0.5\% DMSO), inhibited the increase of HIF1a during OGD, while DMOG stabilized the protein for at least $24 \mathrm{~h}$ (Fig. 2). HIF 1 a was maintained at a lower level at $24 \mathrm{~h}$ with 2 ME2 treatment, but did not differ significantly from with OGD only (Fig. 2).

\section{HIF1 $\alpha$ Inhibition Enhances Necrotic and Apoptotic Cell Death after OGD}

To study the role of HIF1a in the endogenous protective responses following OGD, the HIF1 1 inhibitor $2 \mathrm{ME} 2$ or the stabilizer DMOG was added during and after OGD, to determine the effect on cell viability. The LDH analysis (Fig. 3a) showed that $2 \mathrm{ME} 2(50 \mu \mathrm{M})$ or DMOG $(25 \mu \mathrm{M})$ was not toxic to the neurons under the control normoxic condition. OGD increased cell death from $20.03 \pm 2.64 \%$ (control) to $41.35 \pm 5.76 \%$ (OGD) $24 \mathrm{~h}$ afterwards ( $p<$ 0.05 vs. control). HIF1 $\alpha$ inhibition further augmented neuronal death $(53.57 \pm 1.98 \%, p<0.05$ vs. OGD) suggesting that HIF1 $\alpha$ is involved in protective mechanisms after OGD. There was no difference following DMOG treatment compared to with OGD alone. Increased spectrin cleavage by calcium-sensitive proteases such as calpain and caspases has been used as an indicator of necrotic and apoptotic cell death. Spectrin cleavage leads to an elevated generation of spectrin breakdown products (SBDPs) of 145/150 kDa (indicative of necrotic and excitotoxic neuronal death) and $120 \mathrm{kDa}$ (represents apoptotic death) [37]. As shown in Figure 3b, OGD induced the production of $145 / 150-\mathrm{kDa}$ and $120-\mathrm{kDa}$ SBDPs at 0 $\mathrm{h}$ and $24 \mathrm{~h}$ after OGD $\left({ }^{*} p<0.05,{ }^{* *} p<0.01,{ }^{* * *} p<0.001\right.$ vs. control), which was further increased by HIF1 $\alpha$ inhibition with $2 \mathrm{ME} 2\left(* p<0.05,{ }^{* *} p<0.01\right.$ vs. OGD alone). These data are consistent with the LDH results. In contrast, stabilizing HIF1 $\alpha$ with DMOG attenuated the expression of $145 / 150-\mathrm{kDa}$ SBDPs immediately after OGD, but not $24 \mathrm{~h}$ later.

\section{Epo and VEGF Expression following OGD}

Epo and VEGF are known HIFla substrates that are involved in neuroprotection in the rodent model of neonatal HI and neonatal stroke $[22,38]$. Under our in vitro condition, VEGF expression was slightly increased $24 \mathrm{~h}$ after OGD ( $p<0.05$, OGD vs. control; Fig. 4), while Epo was not induced at these early time points. HIF1 $\alpha$ inhibition with 2ME2 diminished the levels of Epo and VEGF immediately after OGD $(p<0.001$, OGD $2 \mathrm{ME} 2$ vs. OGD alone; Fig. 4), but not 24 h later. DMOG, however, increased the expression of VEGF $24 \mathrm{~h}$ after OGD $(p<0.05$, OGD DMOG vs. OGD alone; Fig. 4). 

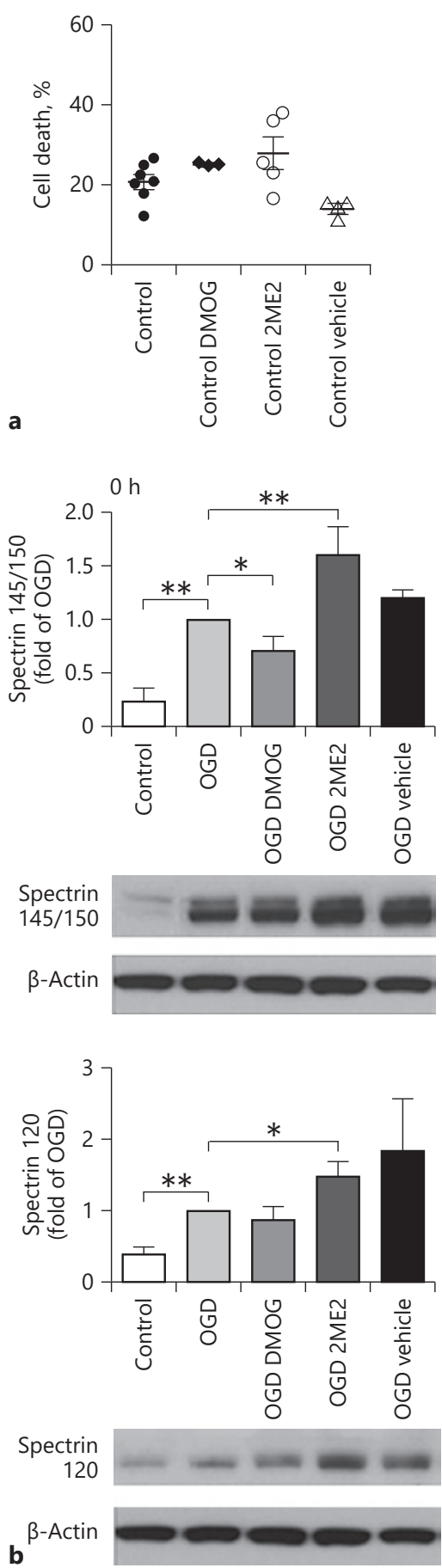
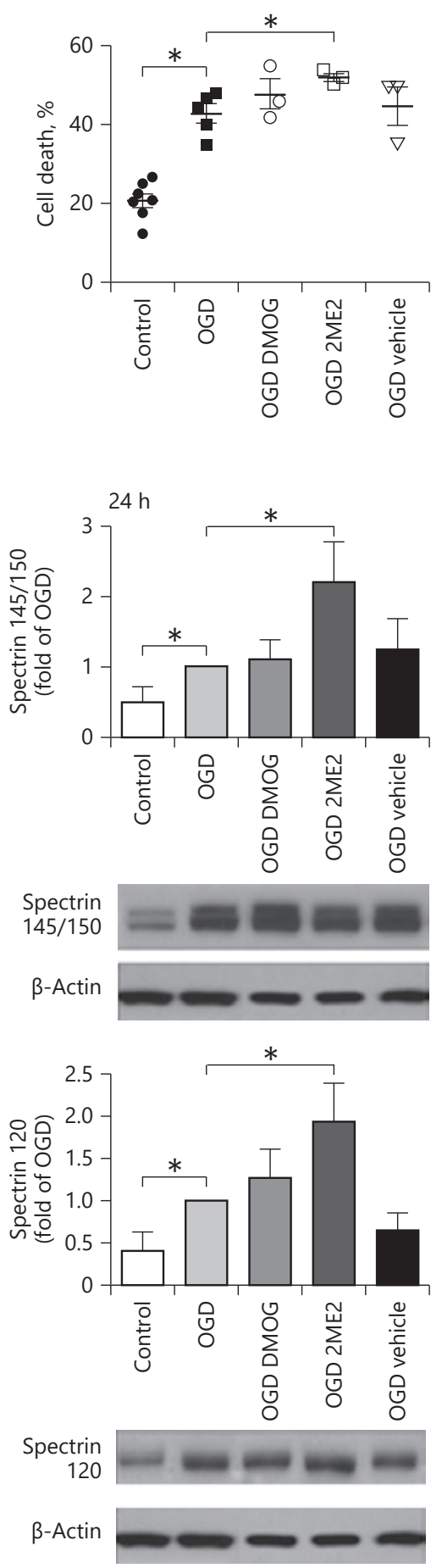

Fig. 3. HIF1 $\alpha$ inhibition enhanced necrotic and apoptotic cell death after OGD. a 2ME2 exposure during and after OGD caused more cell death than OGD alone by LDH assay (right). The drugs were not toxic to control cells (left). ${ }^{*} p<0.05, n=5-7$. b 2 ME2 increased the levels of $145 / 150-\mathrm{kDa}$ and $120-\mathrm{kDa}$ SBDPs at 0 and $24 \mathrm{~h}$ after OGD compared to the OGD alone group. DMOG reduced $145 / 150-\mathrm{kDa}$ SBDP expression right after OGD $\left({ }^{*} p<0.05,{ }^{* *} p<0.01,{ }^{* * *} p<0.001 ; n=4-5\right)$. 

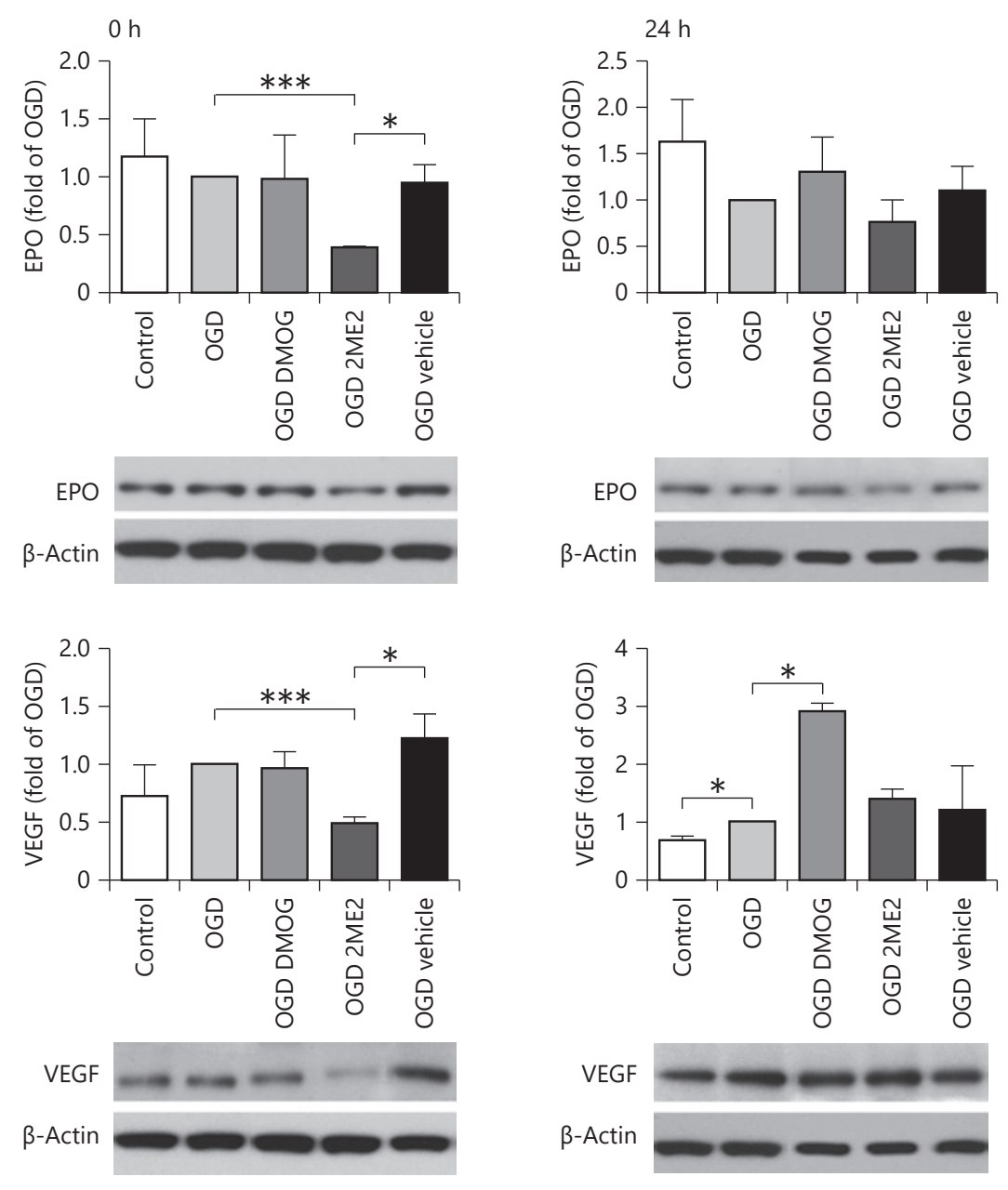

Fig. 4. EPO and VEGF expression following OGD 2ME2 (but not the vehicle control) diminished Epo and VEGF expression at $0 \mathrm{~h}$ compared to the OGD-alone group (*** $p<0.001)$. DMOG increased VEGF levels $24 \mathrm{~h}$ after OGD $(* p<0.05 ; n=3-5)$.

Neuronal-Specific HIF1 $\alpha$ KO Mice Have More Severe

\section{Brain Injury after Neonatal HI}

We showed previously that HIF1 $\alpha$-deficient mice have more exacerbated brain injury at P7 than their WT littermates following HI [21]. At the more mature stage of P9, these mice are similarly more vulnerable to HI brain damage. The expression of HIF1a protein was confirmed to be minimal in the HIF1 $\alpha$ KO mice $24 \mathrm{~h}$ after HI (Fig. 5; ${ }^{*} p<0.05$, WT sham vs. KO sham, ${ }^{* * *} p<0.001$, WT HI vs. KO HI). Compared to the WT pups, the neuron-specific HIF1a KO mice had significantly higher levels of apoptotic cell death, evaluated by the expression of 120 -
kDa SBDPs (Fig. 5 ; * $p<0.05$, WT HI vs. KO HI). These data agree with our observation when the mice were used at P7 in the same HI model.

\section{Discussion}

Using genetic and acute pharmacological manipulation of HIF1a, we examined the function of neuronal HIF $1 \alpha$ and its key effectors that may protect the neonatal brain or immature neurons against $\mathrm{HI}$ injury in vivo and in vitro. We demonstrated that the inhibition of HIF1a 


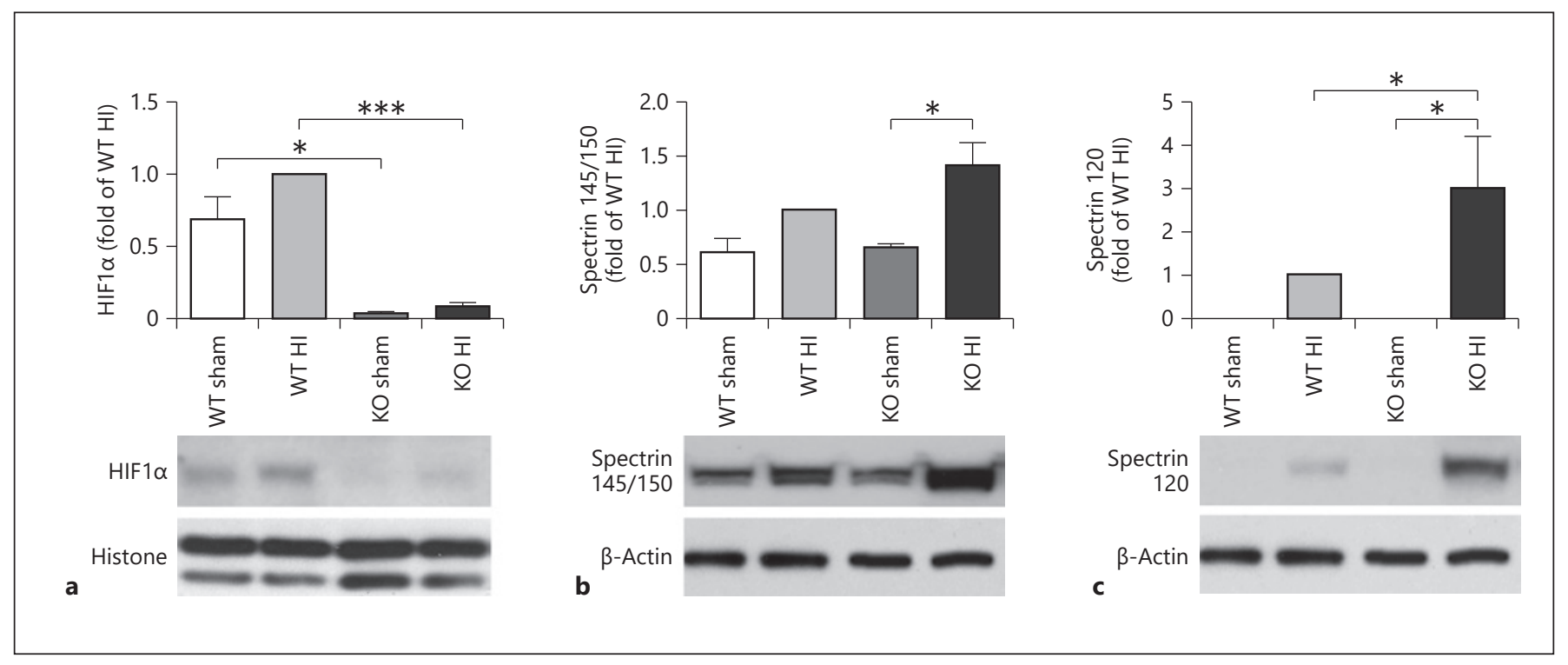

Fig. 5. Neuron-specific HIF1a KO mice had more severe brain injury than WT mice at P9 after HI. a HIF1a expression was abolished in the KO sham and HI-injured animals. The levels of 145/150-kDa SBDPs (b) and $120-\mathrm{kDa}$ SBDPs $(\mathbf{c})$ were significantly higher in the KO mice than in the WT animals at $24 \mathrm{~h}$ post-HI. $\left({ }^{*} p<0.05\right.$, $* * * \quad p<0.001 ; n=4-7)$.

with 2ME2 in cortical neurons or the deletion of neuronal HIF1a in P9 mice increased both necrotic and apoptotic cell death following HI, confirming the role of neuronal HIF1 $\alpha$ signaling in HI neuroprotection in the developing brain. The in vivo findings are in agreement with our previous data using the same HIF1a-deficient mice at P7 [21].

2ME2 is an endogenous metabolite of estradiol and is the most commonly employed HIFla inhibitor. The mechanism for its inhibition on HIF1a in a human tumor cell line and in human umbilical vein endothelial cells is that 2ME2 inhibits HIF1a mRNA translation/de novo synthesis, and its association with microtubules, thereby blocking HIF1 nuclear accumulation and its transcriptional activity [39-41]. In the adult rodent brain, administration of $2 \mathrm{ME} 2$ before or soon after insult protected against global ischemia [42] or middle cerebral artery occlusion (MCAO)-induced brain damage [43, 44], although 1 study reported that 2ME2 given 10 min after ischemia exacerbated apoptotic death in the CA1 region of the hippocampus following global ischemia [45].2ME2 treatment at later time points ( $8 \mathrm{~h}$ after MCAO) was ineffective or even detrimental [46]. This was also true in neonatal HI where $2 \mathrm{ME} 2$ showed protection by reducing brain edema and infarct volume when used 5 min after $\mathrm{HI}$, whereas the protection was lost if it was administered
$3 \mathrm{~h}$ after HI $[47,48]$. It is believed that HIF 1 a induction at an early stage activates the prodeath genes involved in apoptosis and autophagy, while late-stage HIF1 $\alpha$ increases substrates, including VEGF, that improve functional recovery and brain repair $[28,46]$.

In our primary cortical neuronal cultures, $2 \mathrm{ME} 2 \mathrm{effec}-$ tively inhibited HIF1 $\alpha$ accumulation during the $6 \mathrm{~h}$ of OGD. As a consequence, neurons with 2ME2 treatment had significantly more cell death, evaluated by 2 different cell viability assays (LDH measurement and SBDP levels). The increased neuronal death was not due to 2ME2 toxicity because, at the $50 \mu \mathrm{M}$ dose, it did not cause additional death under normoxia when incubated for $30 \mathrm{~h}$. On the other hand, when HIF1 a was stabilized with the PHD inhibitor DMOG, while the LDH assay did not show any changes in cell death, it reduced the levels of $145 / 150-\mathrm{kDa}$ SBDPs right after OGD. DMOG was used at $25 \mu \mathrm{M}$ since the higher concentrations (it was tested at 50, 100, and $150 \mu \mathrm{M})$ were toxic to primary neurons.

These pharmacological data support the protective effects of HIFla in immature neurons, while in the in vivo models 2ME2 may regulate HIF1a in glial cells or other cell populations that collectively modify the overall pattern and severity of cell death. Furthermore, although 2ME2 is relatively specific for HIF1a inhibition, DMOG, as a competitive inhibitor of PHD used for HIF1 $\alpha$ stabi- 
lization, also increases HIF2 $\alpha$ expression. DMOG is a synthetic analog of $\alpha$-ketoglutarate and a dimethyl ester of $\mathrm{N}$-oxalylglycine, and therefore has multiple pharmacological effects including the direct inhibition of mitochondrial function that precedes HIF target gene expression [49]. A more specific strategy for an HIFla gain-offunction study is needed to further clarify its role in neonatal brain $\mathrm{HI}$.

The expression of VEGF and Epo was measured in the primary neurons to identify the HIF1 $\alpha$-mediated protective signaling pathways. These are important HIF1a target substrates implicated in angiogenesis and neurogenesis, respectively, and have therefore been a focus of investigation for promoting recovery and regenerative repair after brain ischemia in rodents and humans [5053]. Under culture conditions, VEGF was upregulated 24 $\mathrm{h}$ after OGD, suggesting that it could be a downstream event following HIF1a activation, while Epo expression remained unchanged in the first $24 \mathrm{~h}$ after the insult. In a rat neonatal stroke model, we demonstrated that HIF1a and VEGF are colocalized in neurons with a similar time course of expression [28]. Epo is increased early in neurons, but later in astrocytes [29].

Recent studies indicate that HIF2 $\alpha$ has emerged as the transcription factor that regulates Epo synthesis in the kidney, liver, and brain [54-56]. Epo transcription and secretion are increased by hypoxia more in cortical astrocytes where HIF $2 \alpha$ is located than those in the neurons [57]. This may explain why we did not observe changes in Epo expression in our primary neurons, or alternatively, Epo may have been induced after $24 \mathrm{~h}$ in our in vitro system. It is not clear whether Epo expression in different cell types or at different time points has distinct significance, but we found that exogenous Epo either given early or delayed after transient neonatal stroke improves histological and behavioral outcomes in P10 rats $[38,58]$. Interestingly, despite VEGF and Epo not being enhanced right after $6 \mathrm{~h}$ of OGD, $2 \mathrm{ME} 2$ reduced their levels at this early time point, in parallel with its inhibition of HIF1a expression. In contrast, overexpression of HIF $1 \alpha$ by DMOG at $24 \mathrm{~h}$ after OGD was accompanied by an increase in VEGF at the same time. The correlated timing and pattern of the changes suggest that VEGF and perhaps Epo are the possible HIF1a downstream mediators for neuroprotection. However, we cannot make this conclusion without inhibition of VEGF or Epo signaling. In our transient neonatal stroke model, treatment with SU5416, a VEGF receptor antagonist, enhanced cell death and limited angiogenesis [59], implying that VEGF plays a role in recovery and repair in brain ischemia. VEGF is also involved in subventricular zone remodeling following neonatal HI, where VEGF-A and VEGF-C are produced by glial progenitor cells and astrocytes. VEGF-A increases astrocyte proliferation and contributes to astrogliogenesis, whereas VEGF-C enhances the proliferation of oligodendrocyte progenitors thereby promoting myelination and white matter regeneration after the injury [60].

The results from neuron-specific HIF1a KO mice are in agreement with our in vitro data on HIF1 $\alpha$ inhibition in primary neurons. They also confirm our previous findings that these mice have, overall, increased brain injury at P7 after neonatal HI [21], suggesting that the HIF1a responses are similar in this range (P7-P9) of the developmental stage. The KO mice showed a significantly higher level of $120-\mathrm{kDa}$ spectrin than the WT pups after $\mathrm{HI}$, but not as much $145 / 150-\mathrm{kDa}$ spectrin, indicating that HIF1 a pathways might protect the cells against apoptosis, rather than the necrotic cell death in our neonatal HI model.

Taken together, we demonstrated, in vitro and in vivo, that HIF1a signaling mediates the endogenous protective responses after neonatal brain HI. It plays a key role in promoting neuronal survival by upregulating its target protective or repair genes, including VEGF and Epo, or possibly via other molecular pathways. Identifying the proteins involved in the stabilization and activation of HIF $1 \alpha$ could be advantageous in treating neonatal brain ischemic conditions and aid in the discovery of new therapeutic approaches to neonatal $\mathrm{HI}$.

\section{Acknowledgements}

This study was supported by the NIH National Institute of Neurological Disorders and Stroke (5R35NS097299 to Dr. Ferriero; RO1NS084057 to Dr. Jiang).

\section{Statement of Ethics}

All animal experiments were approved by the University of California San Francisco (UCSF) institutional animal care and use committee.

\section{Disclosure Statement}

The authors declare they have no conflicts to disclose. 


\section{References}

1 Millar LJ, Shi L, Hoerder-Suabedissen A, Molnár Z. Neonatal Hypoxia Ischaemia: Mechanisms, Models, and Therapeutic Challenges. Front Cell Neurosci. 2017 May;11:78.

2 Semenza GL. Hypoxia-inducible factor 1: master regulator of $\mathrm{O} 2$ homeostasis. Curr Opin Genet Dev. 1998 Oct;8(5):588-94.

3 Semenza GL. HIF-1 and mechanisms of hypoxia sensing. Curr Opin Cell Biol. 2001 Apr; 13(2):167-71

4 Semenza GL. Life with oxygen. Science. 2007 Oct;318(5847):62-4.

5 Lee JW, Bae SH, Jeong JW, Kim SH, Kim KW. Hypoxia-inducible factor (HIF-1)a: its protein stability and biological functions. Exp Mol Med. 2004 Feb;36(1):1-12.

6 Sharp FR, Bernaudin M. HIF1 and oxygen sensing in the brain. Nat Rev Neurosci. 2004 Jun;5(6):437-48.

7 Salceda S, Caro J. Hypoxia-inducible factor 1 alpha (HIF-1 $\alpha$ ) protein is rapidly degraded by the ubiquitin-proteasome system under normoxic conditions. Its stabilization by hypoxia depends on redox-induced changes. J Biol Chem. 1997 Sep;272(36):22642-7.

8 Metzen E, Ratcliffe PJ. HIF hydroxylation and cellular oxygen sensing. Biol Chem. 2004 Mar-Apr;385(3-4):223-30.

9 Chavez A, Miranda LF, Pichiule P, Chavez JC. Mitochondria and hypoxia-induced gene expression mediated by hypoxia-inducible factors. Ann N Y Acad Sci. 2008 Dec;1147(1): 312-20.

10 Majmundar AJ, Wong WJ, Simon MC. Hypoxia-inducible factors and the response to hypoxic stress. Mol Cell. 2010 Oct;40(2):294309.

11 Chavez JC, LaManna JC. Activation of hypoxia-inducible factor- 1 in the rat cerebral cortex after transient global ischemia: potential role of insulin-like growth factor-1. J Neurosci. 2002 Oct;22(20):8922-31.

12 Fan X, Heijnen CJ, van der Kooij MA, Groenendaal F, van Bel F. The role and regulation of hypoxia-inducible factor-1 $1 \alpha$ expression in brain development and neonatal hypoxic-ischemic brain injury. Brain Res Brain Res Rev. 2009 Dec;62(1):99-108.

13 Trollmann R, Gassmann M. The role of hypoxia-inducible transcription factors in the hypoxic neonatal brain. Brain Dev. 2009 Aug; 31(7):503-9.

14 Bergeron M, Yu AY, Solway KE, Semenza GL, Sharp FR. Induction of hypoxia-inducible factor-1 (HIF-1) and its target genes following focal ischaemia in rat brain. Eur J Neurosci. 1999 Dec;11(12):4159-70.

15 Singh N, Sharma G, Mishra V, Raghubir R. Hypoxia inducible factor-1: its potential role in cerebral ischemia. Cell Mol Neurobiol. 2012 May;32(4):491-507.

16 Acker T, Acker H. Cellular oxygen sensing need in CNS function: physiological and pathological implications. J Exp Biol. 2004 Aug;207(Pt 18):3171-88.
17 Chen W, Ostrowski RP, Obenaus A, Zhang JH. Prodeath or prosurvival: two facets of hypoxia inducible factor- 1 in perinatal brain injury. Exp Neurol. 2009 Mar;216(1):7-15.

18 Kietzmann T, Knabe W, Schmidt-Kastner R. Hypoxia and hypoxia-inducible factor modulated gene expression in brain: involvement in neuroprotection and cell death. Eur Arch Psychiatry Clin Neurosci. 2001 Aug;251(4):170-

19 Piret JP, Mottet D, Raes M, Michiels C. Is HIF$1 \alpha$ a pro- or an anti-apoptotic protein? Biochem Pharmacol. 2002 Sep;64(5-6):889-92.

20 Vangeison G, Carr D, Federoff HJ, Rempe DA. The good, the bad, and the cell type-specific roles of hypoxia inducible factor-1 $\alpha$ in neurons and astrocytes. J Neurosci. 2008 Feb; 28(8):1988-93.

21 Sheldon RA, Osredkar D, Lee CL, Jiang X, Mu D, Ferriero DM. HIF-1 $\alpha$-deficient mice have increased brain injury after neonatal hypoxiaischemia. Dev Neurosci. 2009;31(5):452-8.

22 Dzietko M, Derugin N, Wendland MF, Vexler ZS, Ferriero DM. Delayed VEGF treatment enhances angiogenesis and recovery after neonatal focal rodent stroke. Transl Stroke Res. 2013 Apr;4(2):189-200.

23 Geiseler SJ, Morland C. The Janus Face of VEGF in Stroke. Int J Mol Sci. 2018 May; 19(5): 19 .

24 Osredkar D, Sall JW, Bickler PE, Ferriero DM. Erythropoietin promotes hippocampal neurogenesis in in vitro models of neonatal stroke. Neurobiol Dis. 2010 May;38(2):259-65.

25 Wu YW, Gonzalez FF. Erythropoietin: a novel therapy for hypoxic-ischaemic encephalopathy? Dev Med Child Neurol. 2015 Apr;57 Suppl 3:34-9.

26 Jain A, Kratimenos P, Koutroulis I, Jain A, Buddhavarapu A, Ara J. Effect of Intranasally Delivered rh-VEGF165 on Angiogenesis Following Cerebral Hypoxia-Ischemia in the Cerebral Cortex of Newborn Piglets. Int J Mol Sci. 2017 Nov; 18(11):18.

27 Sheldon RA, Lee CL, Jiang X, Knox RN, Ferriero DM. Hypoxic preconditioning protection is eliminated in HIF-1a knockout mice subjected to neonatal hypoxia-ischemia. $\mathrm{Pe}$ diatr Res. 2014 Jul;76(1):46-53.

$28 \mathrm{Mu}$ D, Jiang X, Sheldon RA, Fox CK, Hamrick SE, Vexler ZS, et al. Regulation of hypoxiainducible factor lalpha and induction of vascular endothelial growth factor in a rat neonatal stroke model. Neurobiol Dis. 2003 Dec; 14(3):524-34

$29 \mathrm{Mu}$ D, Chang YS, Vexler ZS, Ferriero DM. Hypoxia-inducible factor $1 \alpha$ and erythropoietin upregulation with deferoxamine salvage after neonatal stroke. Exp Neurol. 2005 Oct; 195(2):407-15.

30 Hamrick SE, McQuillen PS, Jiang X, Mu D, Madan A, Ferriero DM. A role for hypoxiainducible factor-1 $\alpha$ in desferoxamine neuroprotection. Neurosci Lett. 2005 May;379(2): 96-100.
31 Baranova O, Miranda LF, Pichiule P, Dragatsis I, Johnson RS, Chavez JC. Neuron-specific inactivation of the hypoxia inducible factor 1 alpha increases brain injury in a mouse model of transient focal cerebral ischemia. J Neurosci. 2007 Jun;27(23):6320-32.

32 Dragatsis I, Zeitlin S. CaMKIIalpha-Cre transgene expression and recombination patterns in the mouse brain. Genesis. 2000 Feb; 26(2):133-5.

33 Helton R, Cui J, Scheel JR, Ellison JA, Ames C, Gibson C, et al. Brain-specific knock-out of hypoxia-inducible factor- $1 \alpha$ reduces rather than increases hypoxic-ischemic damage. J Neurosci. 2005 Apr;25(16):4099-107.

34 Ryan HE, Poloni M, McNulty W, Elson D, Gassmann M, Arbeit JM, et al. Hypoxia-inducible factor- $1 \alpha$ is a positive factor in solid tumor growth. Cancer Res. 2000 Aug;60(15):4010-5.

35 Sheldon RA, Sedik C, Ferriero DM. Strainrelated brain injury in neonatal mice subjected to hypoxia-ischemia. Brain Res. 1998 Nov; 810(1-2):114-22.

36 Jiang X, Mu D, Manabat C, Koshy AA, Christen S, Täuber MG, et al. Differential vulnerability of immature murine neurons to oxygen-glucose deprivation. Exp Neurol. 2004 Nov; 190(1):224-32.

37 Yan XX, Jeromin A, Jeromin A. Spectrin Breakdown Products (SBDPs) as Potential Biomarkers for Neurodegenerative Diseases. Curr Transl Geriatr Exp Gerontol Rep. 2012 Jun;1(2):85-93.

38 Chang YS, Mu D, Wendland M, Sheldon RA, Vexler ZS, McQuillen PS, et al. Erythropoietin improves functional and histological outcome in neonatal stroke. Pediatr Res. $2005 \mathrm{Jul}$; 58(1):106-11.

39 Mabjeesh NJ, Escuin D, LaVallee TM, Pribluda VS, Swartz GM, Johnson MS, et al. 2ME2 inhibits tumor growth and angiogenesis by disrupting microtubules and dysregulating HIF. Cancer Cell. 2003 Apr;3(4):363-75.

40 Mueck AO, Seeger H. 2-Methoxyestradiolbiology and mechanism of action. Steroids. 2010 Oct;75(10):625-31.

41 Yu T, Tang B, Sun X. Development of Inhibitors Targeting Hypoxia-Inducible Factor 1 and 2 for Cancer Therapy. Yonsei Med J. 2017 May;58(3):489-96.

42 Xin XY, Pan J, Wang XQ, Ma JF, Ding JQ, Yang GY, et al. 2-methoxyestradiol attenuates autophagy activation after global ischemia. Can J Neurol Sci. 2011 Jul;38(4):631-8.

43 Chen C, Hu Q, Yan J, Lei J, Qin L, Shi X, et al. Multiple effects of 2ME2 and D609 on the cortical expression of HIF-1alpha and apoptotic genes in a middle cerebral artery occlusion-induced focal ischemia rat model. J Neurochem. 2007 Sep;102(6):1831-41.

44 Cheng YL, Park JS, Manzanero S, Choi Y, Baik SH, Okun E, et al. Evidence that collaboration between HIF-1a and Notch-1 promotes neuronal cell death in ischemic stroke. Neurobiol Dis. 2014 Feb;62:286-95. 
45 Zhou D, Matchett GA, Jadhav V, Dach N, Zhang JH. The effect of 2-methoxyestradiol, a HIF-1 alpha inhibitor, in global cerebral ischemia in rats. Neurol Res. 2008 Apr;30(3):26871.

46 Yeh SH, Ou LC, Gean PW, Hung JJ, Chang WC. Selective inhibition of early-but not late-expressed HIF-1 $\alpha$ is neuroprotective in rats after focal ischemic brain damage. Brain Pathol. 2011 May;21(3):249-62.

47 Chen W, Jadhav V, Tang J, Zhang JH. HIFlalpha inhibition ameliorates neonatal brain injury in a rat pup hypoxic-ischemic model. Neurobiol Dis. 2008 Sep;31(3):433-41.

48 Chen W, Jadhav V, Tang J, Zhang JH. HIF-1 alpha inhibition ameliorates neonatal brain damage after hypoxic-ischemic injury. Acta Neurochir Suppl (Wien). 2008;102:395-9.

49 Zhdanov AV, Okkelman IA, Collins FW, Melgar S, Papkovsky DB. A novel effect of DMOG on cell metabolism: direct inhibition of mitochondrial function precedes HIF target gene expression. Biochim Biophys Acta. 2015 Oct;1847(10):1254-66.

50 Alexander ML, Hill CA, Rosenkrantz TS, Fitch RH. Evaluation of the therapeutic benefit of delayed administration of erythropoietin following early hypoxic-ischemic injury in rodents. Dev Neurosci. 2012;34(6):515-24.
51 Gonzalez FF, Abel R, Almli CR, Mu D, Wendland M, Ferriero DM. Erythropoietin sustains cognitive function and brain volume after neonatal stroke. Dev Neurosci. 2009;31(5): 403-11.

52 Juul SE, Comstock BA, Heagerty PJ, Mayock DE, Goodman AM, Hauge S, et al. High-Dose Erythropoietin for Asphyxia and Encephalopathy (HEAL): A Randomized Controlled Trial - Background, Aims, and Study Protocol. Neonatology. 2018;113(4):331-8.

53 Traudt CM, McPherson RJ, Bauer LA, Richards TL, Burbacher TM, McAdams RM, et al. Concurrent erythropoietin and hypothermia treatment improve outcomes in a term nonhuman primate model of perinatal asphyxia. Dev Neurosci. 2013;35(6):491503.

54 Haase VH. Regulation of erythropoiesis by hypoxia-inducible factors. Blood Rev. 2013 Jan;27(1):41-53.

55 Ruscher K, Freyer D, Karsch M, Isaev N, Megow D, Sawitzki B, et al. Erythropoietin is a paracrine mediator of ischemic tolerance in the brain: evidence from an in vitro model. J Neurosci. 2002 Dec;22(23):10291301.
56 Yeo EJ, Cho YS, Kim MS, Park JW. Contribution of HIF-1alpha or HIF-2alpha to erythropoietin expression: in vivo evidence based on chromatin immunoprecipitation. Ann Hematol. 2008 Jan;87(1):11-7.

57 Chavez JC, Baranova O, Lin J, Pichiule P. The transcriptional activator hypoxia inducible factor 2 (HIF-2/EPAS-1) regulates the oxygen-dependent expression of erythropoietin in cortical astrocytes. J Neurosci. 2006 Sep; 26(37):9471-81.

58 Larpthaveesarp A, Georgevits M, Ferriero DM, Gonzalez FF. Delayed erythropoietin therapy improves histological and behavioral outcomes after transient neonatal stroke. Neurobiol Dis. 2016 Sep;93:57-63.

59 Shimotake J, Derugin N, Wendland M, Vexler ZS, Ferriero DM. Vascular endothelial growth factor receptor-2 inhibition promotes cell death and limits endothelial cell proliferation in a neonatal rodent model of stroke. Stroke. 2010 Feb;41(2):343-9.

60 Bain JM, Moore L, Ren Z, Simonishvili S, Levison SW. Vascular endothelial growth factors $\mathrm{A}$ and $\mathrm{C}$ are induced in the SVZ following neonatal hypoxia-ischemia and exert different effects on neonatal glial progenitors. Transl Stroke Res. 2013 Apr;4(2): 158-70. 